MSC 35R30, 35Q60, 35Q35

DOI: $10.14529 / \mathrm{mmp} 180105$

\title{
INVERSE PROBLEMS FOR MATHEMATICAL MODELS OF QUASISTATIONARY ELECTROMAGNETIC WAVES IN ANISOTROPIC NONMETALLIC MEDIA WITH DISPERSION
}

\author{
S.G. Pyatkov ${ }^{1,2}$, S.N. Shergin ${ }^{1}$ \\ ${ }^{1}$ Ugra State University, Khanty-Mansyisk, Russian Federation \\ ${ }^{2}$ South Ural State University, Chelyabinsk, Russian Federation \\ E-mail: S_pyatkov@ugrasu.ru, Ssn@ugrasu.ru
}

We consider inverse problems of evolution type for mathematical models of quasistationary electromagnetic waves. It is assumed in the model that the wave length is small as compared with space inhomogeneities. In this case the electric and magnetic potential satisfy elliptic equations of second order in the space variables comprising integral summands of convolution type in time. After differentiation with respect to time the equation is reduced to a composite type equation with an integral summand. The boundary conditions are supplemented with the overdetermination conditions which are a collection of functionals of a solution (integrals of a solution with weight, the values of a solution at separate points, etc.). The unknowns are a solution to the equation and unknown coefficients in the integral operator. Global (in time) existence and uniqueness theorems of this problem and stability estimates are established.

Keywords: Sobolev-type equation; equation with memory; elliptic equation; inverse problem; boundary value problem.

\section{Introduction}

We consider the problems arising in the description of propagation of both electromagnetic waves in anisotropic media [1] and nonstationary interior waves in an incompressible stratified rotating fluid [2]. The peculiarities of propagation of electromagnetic waves in anisotropic media are defined by the corresponding material equations. If the length of a wave is small as compared with space inhomogeneities that these equations can be written in the form accounting for time dispersion only and introducing the potentials of electric and magnetic fields $E=-\nabla \varphi(x, t)$ and $H=-\nabla \psi(x, t)$ and making some transformations we arrive at the equations (see [1], p. 28)

$$
\sum_{i=1}^{3}\left(1+4 \pi \kappa_{i} *\right) \varphi_{x_{i}, x_{i}}=-4 \pi \rho+F_{d}, \quad \sum_{i=1}^{3}\left(1+4 \pi \kappa_{i} *\right) \psi_{x_{i}, x_{i}}=F_{b},
$$

where $\kappa_{i}$ are the diagonal entries of the tensors of electric and magnetic susceptibilities and $\kappa_{i} * \varphi(x, t)=\int_{0}^{t} \kappa_{i}(t-\tau) \varphi(x, \tau) d \tau$. Note that some model problems for nonstationary waves in media with anisotropic dispersion are reduced to integro-differential equations (1) with kernels of convolution operators of the form of a sine, a polynomial, or an exponential function. In these cases it is possible to reduce an initial vector systems of equations by introducing generalized potentials of quasistationary electric and magnetic fields to composite type equations (see [2]) of the form

$$
P_{s}\left(\partial_{t}\right) \Delta \Phi(x, t)+P_{m i j}\left(\partial_{t}\right) \sum_{i, j=1}^{3} \Phi_{x_{i} x_{j}}=F,
$$


where $P_{s}, P_{m i j}$ are polynomials of degrees $s$ and $m$, respectively. At the present article we examine inverse problems on recovering the coefficients $k_{i}$ for general equations of the form

$$
L_{0} u+\sum_{i=1}^{m} \kappa_{i} * L_{i} u=f
$$

where

$$
L_{k} u=\sum_{i, j=1}^{n} a_{i j}^{k}(x, t) u_{x_{i}, x_{j}}+\sum_{i=1}^{n} a_{i}^{k}(x, t)+a_{0}^{k}(x, t) u, \quad(x, t) \in Q=G \times(0, T), G \subset \mathbb{R}^{n} .
$$

The equation (2) is supplemented with the overdetermination conditions

$$
\Psi_{j}(u)(t)=\psi_{j}(t)
$$

where $\Psi_{i}$ are some functionals (the conditions on them are described below), and the boundary conditions

$$
\left.B u\right|_{S}=g(x, t), S=\partial G \times(0, T),
$$

where $B u=u$ or $B u=\sum_{i=1}^{n} \gamma_{i}(x, t) u_{x_{i}}+\sigma(x, t) u$. Similar equations and systems of equations arise in elasticity (materials with memory) [3-5], physics (phase-field models, heat and mass transfer) [6,7], and in many other fields. The most known case is the case of a parabolic (see [3,6-12]) or hyperbolic (see [4,5]) operator $L_{0}$. Even the most general case was studied in which $L_{0}=\partial_{t}-A$ or $L_{0}=\partial_{t}^{2}-A$, with $A$ a generator of an analytic semigroup (see, for instance, [9-12]). The case of a pseudoparabolic operator $L_{0}$ is treated in [13]. In the case of $L_{0}=\partial_{t}$, we arrive at Gurtin-Pipkin-type models (see [14, 15]). Probably, the elliptic case was not considered except for one model situation (see [16]), where $n=1$. We establish global (in time) solvability of the problem (2) - (4) in Sobolev spaces.

\section{Preliminaries}

We employ the Sobolev spaces $W_{p}^{s}(G)$ and Hölder spaces $C^{\alpha}(\bar{G})$. The symbol $L_{p}(0, T ; H)(H$ is a Banach space) stands for the spaces of strongly measurable functions defined on $[0, T]$ with values in $H$ (see the definition of the function spaces, for instance, in [17]).

We assume below that $\Gamma=\partial G \in C^{2}$ (see the definition, for example [18, Sect. 1, Ch. 1]) and that the coefficients of the operators $L_{k}(k=0,1, \ldots, m)$ are real-valued and the operator $L_{0}$ is elliptic, i. e., there exists a constant $\delta_{0}>0$ such that

$$
\sum_{i, j=1}^{m} a_{i j}^{0} \xi_{i} \xi_{j} \geq \delta_{0}|\xi|^{2} \quad \forall \xi \in R^{n}, \quad \forall(x, t) \in \bar{Q} .
$$

We fix the parameter $p>n$ (for simplicity) and suppose that

$$
\begin{gathered}
a_{i j}^{0} \in C(\bar{Q}), \quad a_{i}^{0}, a_{0}^{0} \in C\left([0, T] ; L_{p}(G)\right), a_{i j}^{k} \in L_{\infty}(Q), a_{i j t}^{0}, a_{i j t}^{k} \in L_{p}\left(0, T ; L_{\infty}(G)\right), \\
a_{i}^{k}, a_{0}^{k} \in L_{\infty}\left(0, T ; L_{p}(G)\right), a_{0 t}^{k}, a_{i t}^{k} \in L_{p}(Q) \quad(i, j=1,2, . ., n, k=1,2, \ldots, m), \\
\gamma_{i}, \gamma_{i t}, \sigma, \sigma_{t} \in C^{1}(\bar{S})(i=1, \ldots, n), \quad\left|\sum_{i=1}^{n} \gamma_{i} n_{i}\right| \geq \delta_{1}>0 \forall(x, t) \in S,
\end{gathered}
$$


where $\vec{n}=\left(n_{1}, n_{2}, \ldots, n_{n}\right)$ is the outward unit normal to $S$ and $\delta_{1}$ is a constant. The operator $L_{0}$ is assumed invertible, i. e., the following theorem is valid.

Theorem 1. Let the condition (5) hold. The problem with a parameter

$$
L_{0}(t) u=f(x),\left.\quad B(t) u\right|_{\Gamma}=g(x),
$$

for every $f \in L_{p}(G)(p>n)$ and $g \in W_{p}^{s_{0}}(\Gamma)\left(s_{0}=2-1 / p\right.$ in the case of the Dirichlet conditions and $s_{0}=1-1 / p$ the case of the oblique derivative problem) has a unique solution $u \in W_{p}^{2}(G)$ satisfying the estimate

$$
\|u\|_{W_{p}^{2}(G)} \leq c\left(\|f\|_{L_{p}(G)}+\|g\|_{W_{p}^{s_{0}(\Gamma)}}\right),
$$

where the constant $c$ is independent of $f, g, t \in[0, T]$.

The claim of the theorem holds whenever $\operatorname{ker} L_{0}=0$. In particular, it suffices to require in the case of the Dirichlet boundary conditions that $a_{0}^{0} \leq 0$ a.e. in $Q$ (see the maximum principle [19, Ch. 8]) and in the case of the oblique derivative problem that $a_{0}^{0} \leq 0$ a.e. in $Q$ and $a_{0}^{0}<0$ a.e. in some neighborhood about $S$ (see Proposition 2.3 .2 and Theorem 2.3 .5 in $[20])$.

Corollary 1. As a direct corollary of the claim of the theorem, we have that if $f(x, t) \in$ $C\left([\alpha, \beta] ; L_{p}(G)\right)$ and $g(x, t) \in C\left([\alpha, \beta] ; W_{p}^{s_{0}}(\Gamma)\right)(0 \leq \alpha<\beta \leq T)$ then the problem

$$
L_{0}(t) u=f(x, t),\left.\quad B u\right|_{\Gamma}=g(x, t),
$$

has a unique solution $u \in C\left([\alpha, \beta] ; W_{p}^{2}(G)\right)$ satisfying the estimate

$$
\|u\|_{C\left([\alpha, \beta] ; W_{p}^{2}(G)\right)} \leq c\left(\|f\|_{C\left([\alpha, \beta] ; L_{p}(G)\right)}+\|g\|_{C\left([\alpha, \beta] ; W_{p}^{s_{0}}(\Gamma)\right)}\right),
$$

where the constant $c$ is independent of $f, g, \alpha, \beta$. It is not also difficult to demonstrate that if there exist the generalized derivatives $f_{t} \in L_{p}\left(\alpha, \beta ; L_{p}(G)\right), g_{t} \in L_{p}\left(\alpha, \beta ; W_{p}^{s_{0}}(\Gamma)\right)$ then a solution to the problem $(7)$ is differentiable with respect to $t, u_{t} \in L_{p}\left(\alpha, \beta ; W_{p}^{2}(G)\right)$ and

$$
L_{0}(t) u_{t}=f_{t}(x, t)-L_{0 t} u,\left.\quad B u_{t}\right|_{\Gamma}=g_{t}(x, t)-\left.B_{t} u\right|_{\Gamma},
$$

for almost all $t \in(\alpha, \beta)$ (the coefficients of the operators $L_{0 t}, B_{t}$ are the derivatives with respect to $t$ of the coefficients of $\left.L_{0}, B\right)$. Moreover, the following estimate is valid:

$$
\begin{gathered}
\left\|u_{t}\right\|_{L_{p}\left(\alpha, \beta ; W_{p}^{2}(G)\right)}+\|u\|_{C\left([\alpha, \beta] ; W_{p}^{2}(G)\right)} \leq \\
\leq c\left(\|f\|_{C\left([\alpha, \beta] ; L_{p}(G)\right)}+\|g\|_{C\left([\alpha, \beta] ; W_{p}^{s_{0}}(\Gamma)\right)}+\left\|f_{t}\right\|_{L_{p}\left(\alpha, \beta ; L_{p}(G)\right)}+\left\|g_{t}\right\|_{L_{p}\left(\alpha, \beta ; W_{p}^{s_{0}}(\Gamma)\right)}\right),
\end{gathered}
$$

where the constant $c$ is independent of $\alpha, \beta, f, g$.

Note that the conditions (5) imply that the coefficients $a_{i j}^{k}, a_{i}^{k}, a_{0}^{k}$ belong to the space $C\left([0, T] ; L_{p}(G)\right)$ after a possible modification on a set of zero measure. In what follows we assume this condition to be fulfilled.

Lemma 1. The following inequalities hold:

$$
\|u * v\|_{L_{p}(0, \gamma)} \leq\|u\|_{L_{p}(0, \gamma)}\|v\|_{L_{1}(0, \gamma)},\|u * v\|_{L_{p}(0, \gamma)} \leq \gamma^{1-1 / p}\|u\|_{L_{p}(0, \gamma)}\|v\|_{L_{p}(0, \gamma)}
$$




$$
\begin{gathered}
\|u(t)\|_{L_{\infty}(0, \gamma)} \leq \gamma^{1-1 / p}\left\|u_{t}\right\|_{L_{p}(0, \gamma)}, \quad u(0)=0, \\
\|u(t)\|_{L_{p}(0, \gamma)} \leq \gamma\left\|u_{t}\right\|_{L_{p}(0, \gamma)}, \quad u(0)=0 .
\end{gathered}
$$

The inequalities (9) are known (see, for instance, Lemma 3.1 in [6]). The inequalities (10), (11) are an obvious consequence of the Newton-Leibnitz formula.

Assume that a solution to the problem (2) - (4) possesses the property $u_{t} \in$ $L_{p}\left(0, T ; W_{p}^{2}(G)\right)$ and $u \in C\left([0, T] ; W_{p}^{2}(G)\right)$, the conditions (5) hold, $g \in C\left([0, T] ; W_{p}^{s_{0}}(\Gamma)\right)$, and $g_{t} \in L_{p}\left(0, T ; W_{p}^{s_{0}}(\Gamma)\right), k_{i}(t) \in L_{p}(0, T)$ for all $i$, and $f, f_{t} \in L_{p}(Q)$. Taking $t=0$ in (2), we infer $L_{0}(x, 0) u(x, 0)=f(x, 0)$. Applying Theorem 1, we can find the function $u(x, 0)=u_{0}(x)$ as a solution to the problem (6) at $t=0$. The boundary condition (3) yields

$$
\left.B u_{0}(x)\right|_{\Gamma}=g(x, 0)
$$

The condition (4) implies the necessary solvability condition

$$
\Psi_{j}\left(u_{0}(x)\right)=\psi_{j}(0) \quad j=1,2, \ldots, m .
$$

Next, differentiating (2) with respect to $t$, we infer

$$
\left(L_{0} u\right)_{t}+\int_{0}^{t} \sum_{i=1}^{m} k_{i}(\tau)\left(L_{i} u_{t}(x, t-\tau)+L_{i t} u(t-\tau)\right) d \tau=f_{t}-\sum_{i=1}^{m} k_{i}(t) L_{i}(x, 0) u_{0}(x)
$$

Construct an auxiliary function $\Phi(x, t) \in C\left([0, T] ; W_{p}^{2}(G)\right)$ such that $\Phi_{t} \in$ $L_{p}\left(0, T ; W_{p}^{2}(G)\right),\left.B \Phi\right|_{S}=g(x, t)$, and $\Phi(x, 0)=u_{0}(x)$. Let $\Phi$ be a solution to the problem (7). Making the change of variables $u=v+\Phi$, we obtain the problem

$$
\begin{gathered}
\left(L_{0} v\right)_{t}+\int_{0}^{t} \sum_{i=1}^{m} k_{i}(\tau)\left(L_{i} v\right)_{t}(x, t-\tau) d \tau= \\
=-\sum_{i=1}^{m} k_{i}(t) L_{i}(x, 0) u_{0}(x)-\int_{0}^{t} \sum_{i=1}^{m} k_{i}(\tau)\left(L_{i} \Phi\right)_{t}(x, t-\tau) d \tau=f_{0} \\
\left.B v\right|_{\Gamma}=0, \quad v(x, 0)=0, \\
\Psi_{j}(v)=\psi_{j}-\Psi_{j}(\Phi)=\tilde{\psi}_{j}, j=1,2, \ldots, m .
\end{gathered}
$$

Theorem 2. Assume that $f, f_{t} \in L_{p}(Q)$, the conditions (5), (12), (13) hold, $g \in$ $C\left([0, T] ; W_{p}^{s_{0}}(\Gamma)\right), g_{t} \in L_{p}\left(0, T ; W_{p}^{s_{0}}(\Gamma)\right)(p>n)$, and $\psi_{j} \in W_{p}^{1}(0, T)(j=1,2, \ldots, m)$. Then the problem (15) - (17) of determining the functions $v, k_{1}, \ldots, k_{m}$ from the class $v_{t} \in L_{p}\left(0, T ; W_{p}^{2}(G)\right), v \in C\left([0, T] ; W_{p}^{2}(G)\right), k_{i} \in L_{p}(0, T)(i=1,2, \ldots, m)$ is equivalent to the problem (2) - (4) of determining the functions $u, k_{1}, \ldots, k_{m}$ such that $u_{t} \in$ $L_{p}\left(0, T ; W_{p}^{2}(G)\right), u \in C\left([0, T] ; W_{p}^{2}(G)\right)$, and $k_{i} \in L_{p}(0, T)(i=1,2, \ldots, m)$.

Proof. Actually, the arguments presented before the theorem show that if $u, k_{1}, \ldots, k_{m}$ is a solution to the problem (2) - (4) from the above-pointed class then the functions $v, k_{1}, \ldots, k_{m}$ is a solution to the problem $(15)-(17)$. So it suffices to verify the converse statement. Let $v, k_{1}, \ldots, k_{m}$ is a solution to the problem (15) $-(17)$. Put $u=v+\Phi$. The equalities $f_{t}=\left(L_{0} \Phi\right)_{t}$ and (15) imply that

$$
\partial_{t}\left(L_{0} u\right)+\partial_{t} \int_{0}^{t} \sum_{i=1}^{m} k_{i}(\tau) L_{i} u(x, t-\tau) d \tau=f_{t}
$$


Integrating this equality from 0 to $t$, we derive that

$$
L_{0} u+\int_{0}^{t} \sum_{i=1}^{m} k_{i}(\tau) L_{i} u(x, t-\tau) d \tau=f(t)+L_{0} u(x, 0)-f(x, 0) .
$$

Since $0=v(x, 0)=u(x, 0)-\Phi(x, 0)=u(x, 0)-u_{0}(x), u(x, 0)=u_{0}(x)$, the definition of the function $u_{0}$, yields $L u(x, 0)-f(x, 0)=0$, i. e., the equality (2) holds. The validity of the condition (4) is obvious.

Let $0 \leq \alpha<\beta \leq T$. Define the space $H(\alpha, \beta)$ as the space of functions $v(x, t)$ such that $v_{t} \in L_{p}\left(\alpha, \beta ; W_{p}^{2}(G)\right), v \in C\left([\alpha, \beta] ; W_{p}^{2}(G)\right),\left.B v\right|_{\Gamma}=0$. Endow it with the norm $\left\|\left.v\right|_{H(\alpha, \beta)}=\right\| v\left\|_{C\left([\alpha, \beta] ; W_{p}^{2}(G)\right)}+\right\| v_{t} \|_{L_{p}\left(\alpha, \beta ; W_{p}^{2}(G)\right)}$. In what follows, a norm of a vector is the sum of the norms of its coordinates.

Lemma 2. Let the conditions (5) hold. Then

$$
\begin{aligned}
& \left\|\left(L_{j} v\right)_{t}\right\|_{L_{p}\left(\alpha, \beta ; L_{p}(G)\right)} \leq c\|v\|_{H(\alpha, \beta)} \quad \forall v \in C\left([\alpha, \beta] ; W_{p}^{2}(G)\right): v_{t} \in L_{p}\left(\alpha, \beta ; W_{p}^{2}(G)\right), \\
& \left\|L_{j t} v\right\|_{L_{p}\left(\alpha, \beta ; L_{p}(G)\right)} \leq c\|v\|_{C\left([\alpha, \beta] ; W_{p}^{2}(G)\right)} \forall v \in C\left([\alpha, \beta] ; W_{p}^{2}(G)\right): v_{t} \in L_{p}\left(\alpha, \beta ; W_{p}^{2}(G)\right),
\end{aligned}
$$

where $0 \leq \alpha<\beta \leq T$ and the constant $c$ is independent of $\alpha, \beta, j$.

Proof. The proof is more or less obvious. As an example, we establish (20). The expression $L_{j t} v$ contains the summands $a_{i k t}^{j} v_{x_{i} x_{k}}, a_{k t}^{j} v_{x_{k}}$, and $a_{0 t}^{j} v$. We have

$$
\left\|a_{i k t}^{j} v_{x_{i} x_{k}}\right\|_{L_{p}\left(\alpha, \beta ; L_{p}(G)\right)} \leq\left(\int_{\alpha}^{\beta}\left\|a_{i k t}^{j}\right\|_{L_{\infty}(G)}^{p} d t\right)^{1 / p}\left\|v_{x_{i} x_{k}}\right\|_{L_{\infty}\left(\alpha, \beta ; L_{p}(G)\right)} \leq c_{i k}^{j}(\alpha, \beta)\|v\|_{H(\alpha, \beta)} .
$$

Similarly, we infer

$$
\begin{gathered}
\left\|a_{k t}^{j} v_{x_{k}}\right\|_{L_{p}\left(\alpha, \beta ; L_{p}(G)\right)} \leq\left\|a_{k t}^{j}\right\|_{L_{p}\left(\alpha, \beta ; L_{p}(G)\right)}\left\|v_{x_{k}}\right\|_{L_{\infty}\left(\alpha, \beta ; L_{\infty}(G)\right)} \leq c_{k}^{j}(\alpha, \beta)\|v\|_{H(\alpha, \beta)}, \\
\left\|a_{0 t}^{j} v\right\|_{L_{p}\left(\alpha, \beta ; L_{p}(G)\right)} \leq c_{0}^{j}(\alpha, \beta)\|v\|_{H(\alpha, \beta)} .
\end{gathered}
$$

Here we employ the embedding $W_{p}^{1}(G) \subset L_{\infty}(G)$ (see [17]). We can take the sum of the constants $c_{i k}^{j}(0, T), c_{i}^{j}(0, T), c_{0}^{j}(0, T)$ over all indices as the constant in (20).

Lemma 3. Let the conditions (5) hold. Then the following inequalities hold:

$$
\begin{gathered}
\left\|\int_{0}^{t} k_{j}(\tau)\left(L_{j} w\right)_{t}(x, t-\tau) d \tau\right\|_{L_{p}\left(0, \gamma ; L_{p}(G)\right)} \leq c_{1} \gamma^{1-1 / p}\left\|k_{j}\right\|_{L_{p}(0, \gamma)}\|w\|_{H(0, \gamma)}, \gamma \leq T, \\
\left\|\int_{l}^{t} k_{j}(\tau)\left(L_{j} w\right)_{t}(x, t-\tau) d \tau\right\|_{L_{p}\left(l, l+\gamma ; L_{p}(G)\right)} \leq c_{1} \gamma^{1-1 / p}\left\|k_{j}\right\|_{L_{p}(l, l+\gamma)}\|w\|_{H(0, \gamma)}, l+\gamma \leq T, \\
\left\|\int_{0}^{t-l} k_{j}(\tau)\left(L_{j} w\right)_{t}(x, t-\tau) d \tau\right\|_{L_{p}\left(l, l+\gamma ; L_{p}(G)\right)} \leq c_{1} \gamma^{1-1 / p}\left\|k_{j}\right\|_{L_{p}(0, \gamma)}\|w\|_{H(l, l+\gamma)}, l+\gamma \leq T,
\end{gathered}
$$

valid for every every $w \in C\left([\alpha, \beta] ; W_{p}^{2}(G)\right)$ such that $w_{t} \in L_{p}\left(\alpha, \beta ; W_{p}^{2}(G)\right)$. The constant $c_{1}$ is independent of $\gamma, l, j$. 
Proof. To prove (24), we first use the Minkowski inequality inserting the norm in $L_{p}(G)$ under the integral sign. Next, we apply Lemmas 2 and 3. To establish (25), we use the change of variables. We have

$\left\|\int_{l}^{t} k_{j}(\tau)\left(L_{j} w\right)_{t}(x, t-\tau) d \tau\right\|_{L_{p}\left(l, l+\gamma ; L_{p}(G)\right)}=\left\|\int_{0}^{r} k_{j}\left(\tau_{1}+l\right)\left(L_{j} w\right)_{t}\left(x, r-\tau_{1}\right) d \tau_{1}\right\|_{L_{p}\left(0, \gamma ; L_{p}(G)\right)}$.

Thus, we obtain the integral of the form (24) which is estimated similarly. The estimate of the last integral after the change of variables is reduced to estimating the espression

$$
\left\|\int_{0}^{r} k_{j}(\tau)\left(L_{j} w\right)_{t}(x, r+l-\tau) d \tau\right\|_{L_{p}\left(0, \gamma ; L_{p}(G)\right)},
$$

which is again of the same form as the left-hand side of (24).

Consider the auxiliary equation

$$
L_{0} v_{t}+L_{0 t} v+\int_{0}^{t} \sum_{i=1}^{m} k_{i}(\tau)\left(L_{i} v\right)_{t}(x, t-\tau) d \tau=f_{0}
$$

Let $Q^{\gamma}=G \times(0, \gamma)$. Fix $T_{0} \leq T$.

Theorem 3. Assume that $f_{0} \in L_{p}\left(Q^{T_{0}}\right)(p>n)$, the conditions (5) hold, and $k_{i} \in$ $L_{p}\left(0, T_{0}\right)(i=1,2, \ldots, m)$. Then there exsists a unique solution to the problem (16), (27), such that $v \in H\left(0, T_{0}\right)$. There exists a constant $c>0$ independent of $f$ and $T_{0}$ such that a solution to the problem (16), (27) satisfies the estimate

$$
\|v\|_{C\left(\left[0, T_{0}\right] ; W_{p}^{2}(G)\right)}+\left\|v_{t}\right\|_{L_{p}\left(0, T_{0} ; W_{p}^{2}(G)\right)} \leq c\left\|f_{0}\right\|_{L_{p}\left(Q^{\left.T_{0}\right)}\right.} .
$$

Proof. We reduce the problem to an integral equation. From (27) we have

$$
v(x, t)+L_{0}^{-1} \int_{0}^{t} \int_{0}^{\xi} \sum_{i=1}^{m} k_{i}(\tau)\left(L_{i} v\right)_{\xi}(x, \xi-\tau) d \tau d \xi=L_{0}^{-1} \int_{0}^{t} f_{0}(x, \tau) d \tau=f_{1},
$$

where the operator $L_{0}^{-1} f$ takes a function $f$ onto a solution to the problem (7) with $g=0$. First, we justify a local solvability. We have the equation

$$
v+S(v)=f_{1}
$$

Estimate $\|S(v)\|_{H(0, \gamma)}\left(\gamma \leq T_{0}\right)$. Corollary 1 and Lemma 3 yield

$$
\|S(v)\|_{H(0, \gamma)} \leq c \gamma^{1-1 / p}\|v\|_{H(0, \gamma)}\|\vec{k}\|_{L_{p}(0, \gamma)} \leq c \gamma^{1-1 / p}\|v\|_{H(0, \gamma)}\|\vec{k}\|_{L_{p}\left(0, T_{0}\right)},
$$

where the constant $c$ is independent of $\gamma$ and $\vec{k}=\left(k_{1}, k_{2}, \ldots, k_{m}\right)$. Hence, for $\gamma \leq \gamma_{0}$ with $\gamma_{0}^{1-1 / p} c\|\vec{k}\|_{L_{p}(0, T)}=1 / 2$, we obtain that $\|S(v)\|_{H(0, \gamma)} \leq\|v\|_{H(0, \gamma)} / 2$ and the fixed point theorem implies the solvability of the equation $(29)$ on $\left[0, \gamma_{0}\right]$. Prove that the equation is solvable on every of the segments $\left[0, l \gamma_{0}+\tau_{0}\right]$, with $l \gamma_{0}<T_{0}, l=1,2, \ldots, \tau_{0} \leq \min \left(\gamma_{0}, T_{0}-\right.$ $\left.l \gamma_{0}\right)$. Proceed by induction. Assume that we have already proven the solvability of (29) on the segment $\left[0, l \gamma_{0}\right]$. Rewrite the equation (29) in the form

$$
v(x, t)+S_{0}(v)=f_{1}-S(v)+S_{0}(v)=f_{2},
$$




$$
S_{0}(v)=\left\{\begin{array}{cc}
0, & t \leq l \gamma_{0}, \\
L_{0}^{-1} \int_{k \gamma_{0}}^{t} \int_{0}^{\xi-l \gamma_{0}} \sum_{i=1}^{m} k_{i}(\tau)\left(L_{i} v\right)_{\xi}(x, \xi-\tau) d \tau d \xi, & t \in\left(l \gamma_{0}, l \gamma_{0}+\tau_{0}\right)
\end{array} .\right.
$$

It is easy to make sure that the expression $-S(v)+S_{0}(v)$ contains the values of the function $v$ on the segment $\left[0, k \gamma_{0}\right]$ only and thereby this expression is an already known function. By Corollary 1 and Lemma 3, the operator $S_{0}(v)$ admits the estimate

$$
\left\|S_{0}(v)\right\|_{H\left(0, l \gamma_{0}+\tau_{0}\right)} \leq c \gamma_{0}^{1-1 / p}\|v\|_{H\left(l \gamma_{0}, l \gamma_{0}+\tau_{0}\right)}\|\vec{k}\|_{L_{p}\left(0, \gamma_{0}\right)} \leq\|v\|_{H\left(0, l \gamma_{0}+\tau_{0}\right)} / 2
$$

(as is easily seen, we can assume that the constant $c$ in (33) and that in (30) coincide). Hence, the equation (31) is solvable. Obviously, a solution to the equation (31) with the right-hand side $f_{2}$ is an extension of a solution to the equation (29) on the segment $\left[l \gamma_{0}, l \gamma_{0}+\tau_{0}\right]$.

\section{Main Results}

Write out additional conditions on the data of the problem. We examine the problem (2) - (4) assuming that the functionals $\Psi_{j}$ meet the conditions

$$
\Psi_{j} \in L\left(W_{p}^{2}(G), \mathbb{R}\right), \quad \Psi_{j}\left(u_{0}\right)=\psi_{j}(0), j=1,2, \ldots, m .
$$

The symbol $L(A, B)$ for given spaces $A, B$ stands for the space of linear continuous operators defined on $A$ with values in $B$.

Well-posedness conditions. Assume that $B$ is the matrix with entries $b_{i j}=$ $\Psi_{i}\left(L_{0}^{-1} L_{j}(x, 0) u_{0}(x)\right)$ and there exists a constant $\delta_{2}>0$ such that

$$
|\operatorname{det} B| \geq \delta_{2} \quad \forall t \in[0, T]
$$

where $L_{0}^{-1} f$ is a solution $v_{0}$ to the problem $L_{0} v_{0}=f,\left.\quad B v_{0}\right|_{\Gamma}=0$.

Theorem 4. Assume that $f, f_{t} \in L_{p}(Q)$, the conditions (5), (12), (13), (34), (35) hold, $g \in C\left([0, T] ; W_{p}^{s_{0}}(\Gamma)\right), g_{t} \in L_{p}\left(0, T ; W_{p}^{s_{0}}(\Gamma)\right)(p>n)$, and $\vec{\psi} \in W_{p}^{1}(0, T)(\vec{\psi}=$ $\left(\psi_{1}, \psi_{2}, \ldots, \psi_{m}\right)$. Then there exists a unique solution to the problem (2) - (4) such that $u_{t} \in L_{p}\left(0, T ; W_{p}^{2}(G)\right), u \in C\left([0, T] ; W_{p}^{2}(G)\right), \vec{k} \in L_{p}(0, T), \vec{k}=\left(k_{1}, k_{2}, \ldots, k_{m}\right)$. For any two solutions $\left(u_{1}, \vec{k}_{1}\right),\left(u_{2}, \vec{k}_{2}\right)$ to the problem $(2)-(4)$ relating to the data $f_{i}, g_{i}, \vec{\psi}_{i}(i=1,2)$ satisfying the conditions of the theorem, there is the estimate

$$
\begin{gathered}
\left\|u_{1}-u_{2}\right\|_{C\left([0, T] ; W_{p}^{2}(G)\right)}+\left\|u_{1 t}-u_{2 t}\right\|_{L_{p}\left(0, T ; W_{p}^{2}(G)\right)}+\sum_{i=1}^{m}\left\|k_{1}-k_{2}\right\|_{L_{p}(0, T)} \leq \\
\leq c\left(\left\|f_{1}-f_{2}\right\|_{W_{p}^{1}\left(0, T ; L_{p}(G)\right)}+\left\|g_{1}-g_{2}\right\|_{L_{p}\left(0, T ; W_{p}^{s}(\Gamma)\right)}+\left\|\vec{\psi}_{1}-\vec{\psi}_{2}\right\|_{W_{p}^{1}(0, T)}\right),
\end{gathered}
$$

where the constant $c$ depends, in particular, on the norm of the data in the corresponding spaces and the constants in the condition (35).

Proof. Consider the equivalent problem (see Theorem 2)

$$
\left(L_{0} v\right)_{t}+\int_{0}^{t} \sum_{j=1}^{m} k_{i}(\tau)\left(\left(L_{j} v\right)_{t}(x, t-\tau)+\left(L_{j} \Phi\right)_{t}(x, t-\tau)\right) d \tau+\sum_{j=1}^{m} k_{j}(t) L_{j}(x, 0) u_{0}(x)=0,
$$




$$
\begin{gathered}
\left.B v\right|_{\Gamma}=0, \quad v(x, 0)=0, \\
\Psi_{j}(v)=\tilde{\psi}_{j}, j=1,2, \ldots, m .
\end{gathered}
$$

Construct a system for determining the functions $k_{i}$. Inverting the operator $L_{0}$, we arrive at the equation

$$
\begin{aligned}
v_{t}(x, t)+L_{0}^{-1} L_{0 t} v & +L_{0}^{-1} \int_{0}^{t} \sum_{j=1}^{m} k_{j}(\tau)\left(\left(L_{j} v\right)_{t}(x, t-\tau)+\left(L_{j} \Phi\right)_{t}(x, t-\tau)\right) d \tau+ \\
& +v_{0}(v)=-\sum_{j=1}^{m} k_{j}(t) L_{0}^{-1} L_{j}(x, 0) u_{0}(x)
\end{aligned}
$$

where $L_{0}^{-1} f$ takes a function $f$ onto a solution to the problem (7) with $g=0$ and the function $v_{0}(v)$ is zero in the case of the Dirichlet boundary conditions while $v_{0}(v)$ is a solution to the problem $L_{0} v_{0}=0, B v_{0}=-B_{t} v$ in the case of the oblique derivative problem (the coefficients of the operator $B_{t}$ are the derivatives with respect to $t$ of the coefficients of $B$ ). The equation (37) can be written in either of the forms

$$
\begin{gathered}
L_{0} v(x, t)=-\int_{0}^{t} \int_{0}^{\xi} \sum_{j=1}^{m} k_{j}(\tau)(\tau)\left(\left(L_{j} v\right)_{t}(x, \xi-\tau)+\left(L_{j} \Phi\right)_{t}(x, \xi-\tau)\right) d \tau d \xi- \\
-\sum_{j=1}^{m} \int_{0}^{t} k_{j}(\xi) d \xi L_{j}(x, 0) u_{0}(x)=G(v) \\
v(x, t)=L_{0}^{-1} G(v) .
\end{gathered}
$$

Applying the functional $\Psi_{i}$ to (40), we obtain

$$
\begin{gathered}
\tilde{\psi}_{i t}+\Psi_{i}\left(L_{0}^{-1} L_{0 t} v\right)+\Psi_{i}\left(L_{0}^{-1} \int_{0}^{t} \sum_{j=1}^{m} k_{j}(\tau)\left(L_{j} v\right)_{t}(x, t-\tau) d \tau\right)+\Psi_{i}\left(v_{0}\right)= \\
=-\sum_{j=1}^{m} k_{j}(t) \Psi_{i}\left(L_{0}^{-1} L_{j}(x, 0) u_{0}(x)\right)-\Psi_{i}\left(L_{0}^{-1} \int_{0}^{t} \sum_{j=1}^{m} k_{j}(\tau)\left(L_{j} \Phi\right)_{t}(x, t-\tau) d \tau\right) .
\end{gathered}
$$

In view of (35) this equality implies that

$$
\vec{k}=B^{-1} \vec{F}-B^{-1} A(\vec{k}),
$$

where $\vec{F}$ has the coordinates $F_{i}=-\tilde{\psi}_{i t} \in W_{p}^{1}(0, T)(i=1,2, \ldots, m)$ and the operator $A(\vec{k})$ the coordinates

$A_{i}(\vec{k})=\Psi_{i}\left(L_{0}^{-1} L_{0 t} v\right)+\Psi_{i}\left(L_{0}^{-1} \int_{0}^{t} \sum_{j=1}^{m} k_{j}(\tau)\left(\left(L_{j} v\right)_{t}(x, t-\tau)+\left(L_{j} \Phi\right)_{t}(x, t-\tau)\right) d \tau\right)+\Psi_{i}\left(v_{0}(v)\right)$,

where $v=v(\vec{k})$ is a solution to the problem (37), (38). Thus, we have the system for the vector-function $\vec{k}=\left(k_{1}, k_{2}, . ., k_{m}\right)$. Prove its solvability. Note that by Theorem 3 (used on the segment $[0, \gamma])$, for a given $\vec{k} \in L_{p}(0, \gamma)(\gamma \leq T)$, we can uniquely determine the function $v=v(\vec{k}) \in H(0, \gamma)$ as a solution to the equation (42). Establish some 
estimates. Let $R=2\left\|B^{-1} \vec{F}\right\|_{L_{p}(0, T)}$. We look for a vector $\vec{k}$ in the ball $B_{R}^{\gamma}=\left\{\vec{k} \in L_{p}(0, \gamma)\right.$ : $\left.\|\vec{k}\|_{L_{p}(0, \gamma)} \leq R\right\}$. Let $\vec{k} \in B_{R}^{\gamma}$. Estimate the quantity $\left\|L_{0}^{-1} G(v)\right\|_{H(0, \gamma)}$. We have

$$
G(v)-G(0)=\int_{0}^{t} \int_{0}^{\xi} \sum_{j=1}^{m} k_{j}(\tau)(\tau)\left(L_{j} v\right)_{t}(x, \xi-\tau) d \tau d \xi .
$$

Corollary 1, Lemma 4, and the inequalities (11) imply that

$$
\begin{gathered}
\left\|L_{0}^{-1}(G(v)-G(0))\right\|_{H(0, \gamma)}=\left\|L_{0}^{-1}(G(v)-G(0))\right\|_{H(0, \gamma)} \leq c_{1} \gamma^{1-1 / p}\|\vec{k}\|_{L_{p}(0, \gamma)}\|v\|_{H(0, \gamma)} \\
\left\|L_{0}^{-1} G(0)\right\|_{H(0, \gamma)} \leq c_{1} \gamma^{1-1 / p}\|\vec{k}\|_{L_{p}(0, \gamma)}\|\Phi\|_{H(0, \gamma)}+c_{2}\|\vec{k}\|_{L_{p}(0, \gamma)}
\end{gathered}
$$

Here $c_{1}, c_{2}$ are some constants independent of $\gamma$ and the unknowns. Thus, if

$$
\gamma_{0}^{1-1 / p} c_{1} R=1 / 2
$$

then, for $\gamma \leq \gamma_{0}$, a solution to the equation (42) satisfies the estimate

$$
\|v\|_{H(0, \gamma)} \leq 2\|\vec{k}\|_{L_{p}(0, \gamma)}\left(c_{1}\|\Phi\|_{H(0, T)} \gamma_{0}^{1-1 / p}+c_{2}\right)=2\|\vec{k}\|_{L_{p}(0, \gamma)} c_{3},
$$

which can also rewritten as

$$
\|v\|_{H(0, \gamma)} \leq 2 R c_{3} .
$$

Proceed with the estimates for the summands in (44). Corollary 1 and the trace theorems [17, Sect. 4.7] yield

$$
\left\|v_{0}\right\|_{L_{p}\left(\alpha, \beta ; W_{p}^{2}(G)\right)} \leq c\left\|B_{t} v\right\|_{L_{p}\left(\alpha, \beta ; W_{p}^{s_{0}}(\Gamma)\right)} \leq c_{4}\|v\|_{L_{p}\left(\alpha, \beta ; W_{p}^{2-1 / p}(\Gamma)\right)} \leq c_{5}\|v\|_{L_{p}\left(\alpha, \beta ; W_{p}^{2}(G)\right)},
$$

where the constant $c_{5}$ is independent of $0 \leq \alpha<\beta \leq T$. Let $\kappa_{0}=\max _{i}\left\|\Psi_{i}\right\|_{L\left(W_{p}^{2}(G), \mathbb{R}\right) \text {. In }}$ view of $(10),(34),(48),(50)$, we infer

$$
\begin{aligned}
\sum_{i=1}^{m}\left\|\Psi_{i}\left(v_{0}\right)\right\|_{L_{p}(0, \gamma)} \leq & \kappa_{0} c_{5}\|v\|_{L_{p}\left(0, \gamma ; W_{p}^{2}(G)\right)} \leq c_{6} \gamma^{1-1 / p}\left\|v_{t}\right\|_{L_{p}\left(0, \gamma ; W_{p}^{2}(G)\right)} \leq \\
& \leq 2 c_{3} c_{6} \gamma^{1-1 / p}\|\vec{k}\|_{L_{p}(0, \gamma)} .
\end{aligned}
$$

Using the arguments those in the derivation of (20), (10), Corollary 1, and (48), we obtain

$$
\begin{aligned}
\sum_{j=1}^{m}\left\|\Psi_{j}\left(L_{0}^{-1} L_{0 t} v\right)\right\|_{L_{p}(0, \gamma)} & \leq \kappa_{0} c_{7}\|v\|_{L_{p}\left(0, \gamma ; W_{p}^{2}(G)\right)} \leq c_{8} \gamma^{1-1 / p}\left\|v_{t}\right\|_{L_{p}\left(0, \gamma ; W_{p}^{2}(G)\right)} \leq \\
& \leq 2 c_{3} c_{8} \gamma^{1-1 / p}\|\vec{k}\|_{L_{p}(0, \gamma)},
\end{aligned}
$$

where the constant $c_{8}$ is independent of $\gamma$ and $\vec{k}=\left(k_{1}, k_{2}, \ldots, k_{m}\right)$. Next, using (34), Corollary 1, and Lemma 3, we have

$$
\begin{gathered}
\sum_{i=1}^{m}\left\|\Psi_{i}\left(L_{0}^{-1} \int_{0}^{t} \sum_{j=1}^{m} k_{j}(\tau)\left(\left(L_{j} v\right)_{t}(x, t-\tau)+\left(L_{j} \Phi\right)_{t}(x, t-\tau)\right) d \tau\right)\right\|_{L_{p}(0, \gamma)} \leq \\
\leq \kappa_{0} c_{1}\|\vec{k}\|_{L_{p}(0, \gamma)} \gamma^{1-1 / p}\left(\|v\|_{H(0, \gamma)}+\|\Phi\|_{H(0, T)}\right) \leq\|\vec{k}\|_{L_{p}(0, \gamma)} c_{9} \gamma^{1-1 / p},
\end{gathered}
$$

where $c_{9}=\kappa_{0} c_{1}\left(2 R c_{3}+\|\Phi\|_{H(0, T)}\right)$. The estimates $(51)-(53)$ ensure that

$$
\left\|B^{-1} A(\vec{k})\right\|_{L_{p}(0, \gamma)} \leq\|\vec{k}\|_{L_{p}(0, \gamma)} \gamma^{1-1 / p} c_{10}, c_{10}=\left(2 c_{3}\left(c_{6}+c_{8}\right)+c_{9}\right) .
$$


Choose $\gamma_{1} \leq \gamma_{0}$ such that $c_{10} \gamma_{1}^{1-1 / p}=1 / 2$. In this case, for $\gamma \leq \gamma_{1}$, the operator $B^{-1} \vec{F}-$ $B^{-1} A(\vec{k})$ takes the ball $B_{R}^{\gamma}$ into itself. Demonstrate that it is also contractive for an appropriate $\gamma$. Let $\vec{k}^{1}, \vec{k}^{2} \in B_{R}^{\gamma}\left(\gamma \leq \gamma_{1}\right)$. Denote by $v_{1}, v_{2}$ the corresponding solutions to the equation (42). We have

$$
\begin{gathered}
L_{0} v_{i}(x, t)=-\int_{0}^{t} \int_{0}^{\xi} \sum_{j=1}^{m} k_{j}^{i}(\tau)\left(L_{j} v_{i}\right)_{t}(x, \xi-\tau) d \tau d \xi- \\
-\sum_{j=1}^{m} \int_{0}^{t} k_{j}^{i}(\xi) d \xi L_{j}(x, 0) u_{0}(x)-\int_{0}^{t} \int_{0}^{\xi} \sum_{j=1}^{m} k_{j}^{i}(\tau)\left(L_{j} \Phi\right)_{t}(x, \xi-\tau) d \tau=G\left(v_{i}\right), i=1,2 .
\end{gathered}
$$

Subtracting these equalities, we obtain that

$$
\begin{gathered}
L_{0}\left(v_{1}-v_{2}\right)=-\int_{0}^{t} \int_{0}^{\xi} \sum_{j=1}^{m}\left(k_{j}^{1}-k_{j}^{2}\right)(\tau)\left(L_{j} v_{1}\right)_{t}(x, \xi-\tau)+k_{j}^{2}(\tau)\left(L_{j} v_{1}-L_{j} v_{2}\right)_{t}(x, \xi-\tau) d \tau d \xi- \\
-\sum_{j=1}^{m} \int_{0}^{t}\left(k_{j}^{1}-k_{j}^{2}\right)(\xi) d \xi L_{j}(x, 0) u_{0}(x)-\int_{0}^{t} \int_{0}^{\xi} \sum_{j=1}^{m}\left(k_{j}^{1}-k_{j}^{2}\right)(\tau)\left(L_{j} \Phi\right)_{t}(x, \xi-\tau) d \tau .
\end{gathered}
$$

As before in (48) (see also (45) and (47)), we have

$$
\left\|v_{1}-v_{2}\right\|_{H(0, \gamma)} \leq 4 \gamma^{1-1 / p} c_{1} c_{3} R\left\|\overrightarrow{k_{1}}-\overrightarrow{k_{2}}\right\|_{L_{p}(0, \gamma)}+2 c_{3}\left\|\overrightarrow{k_{1}}-\overrightarrow{k_{2}}\right\|_{L_{p}(0, \gamma)} \leq\left\|\overrightarrow{k_{1}}-\overrightarrow{k_{2}}\right\|_{L_{p}(0, \gamma)} 4 c_{3}
$$

Thus, we obtain one more additional summand as compared with the estimate (48). Next, consider the difference $A\left(\vec{k}_{1}\right)-A\left(\vec{k}_{2}\right)$. We have

$$
\begin{aligned}
& A_{i}\left(\vec{k}_{1}\right)-A_{i}\left(\vec{k}_{2}\right)=\Psi_{i}\left(L_{0}^{-1} \int_{0}^{t} \sum_{j=1}^{m} k_{j}^{1}(\tau)\left(L_{j} v_{1}\right)_{t}(x, t-\tau)-k_{j}^{2}(\tau)\left(L_{j} v_{2}\right)_{t}(x, t-\tau) d \tau\right)+ \\
+ & \Psi_{i}\left(L_{0}^{-1} L_{t}\left(v_{1}-v_{2}\right)\right)+\Psi_{i}\left(v_{0}\left(v_{1}-v_{2}\right)\right)+\Psi_{i}\left(L_{0}^{-1} \int_{0}^{t} \sum_{j=1}^{m}\left(k_{j}^{1}-k_{j}^{2}\right)(\tau)\left(L_{j} \Phi\right)_{t}(x, t-\tau) d \tau\right) .
\end{aligned}
$$

Repeating the arguments with use of the estimates (49), (57) (valid for the functions $\left.v_{1}, v_{2}\right)$, we conclude that

$$
\left\|B^{-1} A\left(\vec{k}^{1}\right)-B^{-1} A\left(\vec{k}^{2}\right)\right\|_{L_{p}(0, \gamma)} \leq\left\|\vec{k}^{1}-\vec{k}^{2}\right\|_{L_{p}(0, \gamma)} \gamma^{1-1 / p} c_{11}, c_{11}=\left(c_{10}+4 \kappa_{0} c_{1} R c_{3}\right) .
$$

Next, we can find $\gamma_{2} \leq \gamma_{1}$ such that $\gamma_{2}^{1-1 / p} c_{11}=1 / 2$. In this case, for $\gamma \leq \gamma_{2}$, the equation (44) is uniquely solvable in the ball $B_{R}^{\gamma}$.

Proceed with the question of global (in time) solvability of (44). We argue as in the proof of Theorem 3. Demonstrate that there exists $\gamma_{3} \leq \gamma_{2}$ such that the solvability of the system $(44)$ on the segment $\left[0, l \gamma_{3}\right](l=1,2, \ldots$,$) implies the solvability of this system on$ $\left[l \gamma_{3}, l \gamma_{3}+\tau_{0}\right]$, where $\tau_{0}=\min \left(\gamma_{3}, T-l \gamma_{3}\right)$. Assume that the system is solvable on $\left[0, l \gamma_{3}\right]$ $\left(l \gamma_{3}<T\right)$. Put

$$
\tilde{k}(t)=\left\{\begin{array}{cc}
\vec{k}(t), & t \in\left[l \gamma_{3}, l \gamma_{3}+\tau_{0}\right] \\
0, & t<l \gamma_{3}
\end{array}, \quad \hat{k}(t)=\left\{\begin{array}{cc}
0, & t \in\left[l \gamma_{3}, l \gamma_{3}+\tau_{0}\right] \\
\vec{k}(t), & t<l \gamma_{3}
\end{array} .\right.\right.
$$

The function $\hat{k}(t)$ is already known and we need to determine the function $\tilde{k}(t)$. Using the notation $S_{0}(v)$ of Theorem 3, where $\gamma_{0}$ is replaced with $\gamma_{3}$, we rewrite (41) in the form

$$
v+S_{0} v=S_{1}(\tilde{k})+f_{3}
$$


where the right-hand side coincide with $L_{0}^{-1} G(v)$ for $t \leq l \gamma_{3}$ and, for $t>l \gamma_{3}$, we have

$$
\begin{gathered}
S_{1}(\tilde{k})=-L_{0}^{-1} \int_{0}^{t} \int_{0}^{\xi} \sum_{j=1}^{m} \tilde{k}_{j}(\tau) L_{j}(v+\Phi)_{\xi}(x, \xi-\tau) d \tau d \xi-\sum_{j=1}^{m} L_{0}^{-1} \int_{0}^{t} \tilde{k}_{j}(\xi) d \xi L_{j}(x, 0) u_{0}(x), \\
f_{3}=-L_{0}^{-1} \int_{0}^{t} \int_{0}^{\xi} \sum_{j=1}^{m} \hat{k}_{j}(\tau) L_{j}(v+\Phi)_{\xi}(x, \xi-\tau) d \tau d \xi- \\
-L_{0}^{-1} \sum_{j=1}^{m} \int_{0}^{t} \hat{k}_{j}(\xi) d \xi L_{j}(x, 0) u_{0}(x)+S_{0}(v) .
\end{gathered}
$$

Note that the function $f_{3}$ is calculated with the use of the values of the functions $v, k$ on the segment $\left[0, l \gamma_{2}\right]$ and thus we can assume that it is a known function. We can see from (59) that $v$ can be expressed trough $\tilde{k}$ linearly. The proof of the estimate (45), Lemma 4 , and the definition of the quantity $\gamma_{2}$ imply that

$$
\left\|S_{0} v\right\|_{H\left(0, l \gamma_{3}+\tau_{0}\right)} \leq c_{1} \gamma_{3}^{1-1 / p}\|\vec{k}\|_{L_{p}\left(0, \gamma_{3}\right)}\|v\|_{H\left(l \gamma_{3}, l \gamma_{3}+\tau_{0}\right)} \leq\|v\|_{H\left(l \gamma_{3}, l \gamma_{3}+\tau_{0}\right)} / 2
$$

Let $v_{1}=\left(I+S_{0}\right)^{-1} S_{1}(\tilde{k})$. The estimate (60) yields $\left\|\left(I+S_{0}\right)^{-1} v\right\|_{H\left(0, l \gamma_{3}+\tau_{0}\right)} \leq 2\|v\|_{H\left(0, l \gamma_{3}+\tau_{0}\right)}$ for all $v \in H\left(0, l \gamma_{3}+\tau_{0}\right)$. In this case Corollary 1, Lemma 3, and (47) - (49) imply that

$$
\begin{gathered}
\left\|v_{1}\right\|_{H\left(0, l \gamma_{3}+\tau_{0}\right)} \leq 2 c_{1} \gamma_{3}^{1-1 / p}\|\tilde{k}\|_{L_{p}\left(l \gamma_{3}, l \gamma_{3}+\tau_{0}\right)}\left(\|v\|_{H\left(0, \gamma_{3}\right)}+\|\Phi\|_{H\left(0, \gamma_{3}\right)}\right)+ \\
+2 c_{2}\|\tilde{k}\|_{L_{p}\left(l \gamma_{3}, l \gamma_{3}+\tau_{0}\right)} \leq 4 c_{3}\|\tilde{k}\|_{L_{p}\left(l \gamma_{3}, l \gamma_{3}+\tau_{0}\right)} .
\end{gathered}
$$

Hence, the function $v=v_{1}+\left(I+S_{0}\right)^{-1} f_{3}$ is estimated by the quantity

$$
\|v\|_{H\left(0, l \gamma_{3}+\tau_{0}\right)} \leq 4 c_{3}\|\tilde{k}\|_{L_{p}\left(l \gamma_{3}, l \gamma_{3}+\tau_{0}\right)}+2\left\|f_{3}\right\|_{H\left(0, l \gamma_{3}+\tau_{0}\right)} .
$$

Write out the representation for $A_{j}(\vec{k})$ for $t \geq l \gamma_{3}$. We have

$$
\begin{gathered}
A_{i}(\vec{k})=A_{i}(\tilde{k})+f_{4 i}, A_{i}(\tilde{k})=\Psi_{i}\left(L_{0}^{-1} L_{0 t} v_{1}+v_{0}\left(v_{1}\right)\right)+ \\
+\Psi_{i}\left(L_{0}^{-1} \int_{0}^{t} \sum_{j=1}^{m} \tilde{k}_{j}(\tau) L_{j}(v+\Phi)_{t}(x, t-\tau) d \tau\right)+\Psi_{i}\left(L_{0}^{-1} \int_{0}^{t-l \gamma_{3}} \sum_{j=1}^{m} \hat{k}_{j}(\tau)\left(L_{j} v_{1}\right)_{t}(x, t-\tau) d \tau\right) \\
f_{4 i}=\Psi_{i}\left(L_{0}^{-1} L_{0 t}\left(I+S_{0}\right)^{-1} f_{3}\right)+\Psi_{i}\left(v_{0}\left(\left(I+S_{0}\right)^{-1} f_{3}\right)\right)+ \\
+\Psi_{i}\left(L_{0}^{-1} \int_{0}^{t} \sum_{j=1}^{m} \hat{k}_{j}(\tau)\left(L_{j} \Phi\right)_{t}(x, t-\tau) d \tau\right)+\Psi_{i}\left(L_{0}^{-1} \int_{t-\gamma_{3} l}^{t} \sum_{j=1}^{m} \hat{k}_{j}(\tau)\left(L_{j} v\right)_{t}(x, t-\tau) d \tau\right)+ \\
\Psi_{i}\left(L_{0}^{-1} \int_{0}^{t-l \gamma_{3}} \sum_{j=1}^{m} \hat{k}_{j}(\tau)\left(L_{j}\left(I+S_{0}\right)^{-1} f_{3}\right)_{t}(x, t-\tau) d \tau\right) .
\end{gathered}
$$

The function $f_{4 i}$ depends on the values of $k$ on the segment $\left(0, l \gamma_{3}\right)$. The remaining expression is a linear operator of the argument $\tilde{k}$. Establish some estimates. Note that the support of $v_{1}$ belongs to the segment $\left[l \gamma_{2}, l \gamma_{2}+\tau_{0}\right]$. As before on the proof of the estimates (51) and (52), we derive that

$$
\begin{gathered}
\sum_{i=1}^{m}\left(\| \Psi_{i}\left(L_{0}^{-1} L_{0 t} v_{1}\left\|_{L_{p}\left(l \gamma_{3}, l \gamma_{3}+\tau_{0}\right)}+\right\| \Psi_{i}\left(v_{0}\left(v_{1}\right)\right) \|_{L_{p}\left(l \gamma_{3}, l \gamma_{3}+\tau_{0}\right)}\right) \leq\right. \\
\leq\left(c_{6}+c_{8}\right) \gamma_{3}^{1-1 / p}\left\|v_{1}\right\|_{H\left(l \gamma_{3}, l \gamma_{3}+\tau_{0}\right)} \leq \gamma_{3}^{1-1 / p}\left(c_{6}+c_{8}\right) 4 c_{3}\|\tilde{k}\|_{L_{p}\left(l \gamma_{3}, l \gamma_{3}+\tau_{0}\right)} .
\end{gathered}
$$


Involving the arguments of the proof of (53), we infer

$$
\begin{aligned}
& \sum_{i=1}^{m}\left\|\Psi_{i}\left(L_{0}^{-1} \int_{0}^{t} \sum_{j=1}^{m} \tilde{k}_{j}(\tau)\left(\left(L_{j} v\right)_{t}(x, t-\tau)+\left(L_{j} \Phi\right)_{t}(x, t-\tau)\right) d \tau\right)\right\|_{L_{p}\left(l \gamma_{3}, l \gamma_{3}+\tau_{0}\right)} \leq \\
& \leq \kappa_{0} c_{1} \gamma_{3}^{1-1 / p}\|\tilde{k}\|_{L_{p}\left(l \gamma_{3}, l \gamma_{3}+\tau_{0}\right)}\left(\|v\|_{H\left(0, \gamma_{3}\right)}+\|\Phi\|_{H(0, T)}\right) \leq \gamma_{3}^{1-1 / p}\|\tilde{k}\|_{L_{p}\left(l \gamma_{3}, l \gamma_{3}+\tau_{0}\right)} c_{9} .
\end{aligned}
$$

Moreover, we have

$$
\begin{gathered}
\sum_{i=1}^{m} \| \Psi_{i}\left(L_{0}^{-1} \int_{0}^{t-l \gamma_{3}} \sum_{j=1}^{m} \hat{k}_{j}(\tau)\left(\left(L_{j} v_{1}\right)_{t}(x, t-\tau) d \tau\right) \|_{L_{p}\left(l \gamma_{3}, l \gamma_{3}+\tau_{0}\right)} \leq\right. \\
\leq \kappa_{0} c_{1} \gamma_{3}^{1-1 / p}\|\vec{k}\|_{L_{p}\left(0, \gamma_{3}\right)} 4 c_{3}\|\tilde{k}\|_{L_{p}\left(l \gamma_{3}, l \gamma_{3}+\tau_{0}\right)} \leq \kappa_{0} c_{1} \gamma_{3}^{1-1 / p} 2 R c_{3}\|\tilde{k}\|_{L_{p}\left(l \gamma_{3}, l \gamma_{3}+\tau_{0}\right)} .
\end{gathered}
$$

Thus, the estimate

$$
\left\|B^{-1} A(\tilde{k})\right\|_{L_{p}\left(l \gamma_{3}, l \gamma_{3}+\tau_{0}\right)} \leq \gamma_{3}^{1-1 / p}\|\tilde{k}\|_{L_{p}\left(l \gamma_{3}, l \gamma_{3}+\tau_{0}\right)}\left(\left(c_{6}+c_{8}\right) 4 c_{3}+c_{9}+\kappa_{0} c_{1} 2 R c_{3}\right)
$$

is valid. Hence, if we choose $\gamma_{3}$ so that

$$
\gamma_{3}^{1-1 / p}\left(\left(c_{6}+c_{8}\right) 4 c_{3}+c_{9}+\kappa_{0} c_{1} 2 R c_{3}\right)=1 / 2,
$$

then the operator $B^{-1} A(\tilde{k})$ is contractive. Therefore, if the system (44) is solvable on the segment $\left[0, l \gamma_{3}\right](l=1,2, \ldots$,$) then the system is solvable on \left[l \gamma_{3}, l \gamma_{3}+\tau_{0}\right]$, where $\tau_{0}=\min \left(\gamma_{3}, T-l \gamma_{3}\right)$. The latter implies that the system (44) is solvable on $[0, T]$. Show that the corresponding function $v=v(k)$ (a solution to the problem (37), (38)) meets the conditions (39). Inverting the operator $L_{0}$, we validate the equality (40). Applying the functionals $\Psi_{j}$ to (40), we obtain that

$$
\begin{aligned}
& \left(\Psi_{i}(v)\right)_{t}+\Psi_{i}\left(L_{0}^{-1} L_{0 t} v\right)+\Psi_{i}\left(L_{0}^{-1} \int_{0}^{t} \sum_{j=1}^{m} k_{j}(\tau)\left(L_{j} v\right)_{t}(x, t-\tau) d \tau\right)+\Psi_{i}\left(v_{0}\right)= \\
= & -\sum_{j=1}^{m} k_{j}(t) \Psi_{i}\left(L_{0}^{-1} L_{j}(x, 0) u_{0}(x)\right)-\Psi_{i}\left(L_{0}^{-1} \int_{0}^{t} \sum_{j=1}^{m} k_{j}(\tau)\left(L_{j} \Phi\right)_{t}(x, t-\tau) d \tau\right) .
\end{aligned}
$$

Subtracting this equality from (43), we arrive at the equality $\left(\Psi_{i}(v)\right)_{t}-\tilde{\psi}_{i t}=0$, or (in view of (13), (17)) $\Psi_{i}(v)=\tilde{\psi}_{i}$, i. e., the equalities (39) are fulfilled. The claim follows from Theorem 2.

The proof of the estimate (36) is in line with the proof of the existence. We just repeat the arguments paying attention to constants in the corresponding estimates.

Acknowledgement. The authors were supported by RFBR (Grant 18-01-00620) and by the Act 211 of the Government of the Russian Federation (contract 02.A03.21.0011).

\section{References}

1. Sveshnikov A.G., Alshin A.B., Korpusov M.O., Pletner U.D. Lineynye $i$ nelineynye uravneniya sobolevskogo tipa [Linear and Non-Linear Sobolev Equations]. Moscow, Fizmatlit, 2007. (in Russian) 
2. Gabov S.A., Sveshnikov A.G. Lineynye zadachi teorii nestatsionarnykh vnutrennikh voln [Linear Problems of the Theory of Nonstationary Interior Waves]. Moscow, Nauka, 1990. (in Russian)

3. Lorenzi A., Paparone I. Direct and Inverse Problems in the Theory of Materials with Memory. Rendiconti del Seminario Matematico della Universita di Padova, 1992, vol. 87, p. 105-138.

4. Janno J., Von Wolfersdorf L. Inverse Problems for Identification of Memory Kernels in Viscoelasticity. Mathematical Methods in the Applied Sciences, 1997, vol. 20, pp. 291-314. DOI: 10.1002/(SICI)1099-1476(19970310)20:4<291::AID-MMA860>3.0.CO;2-W

5. Durdiev D.K., Safarov Zh.Sh. Inverse Problem of Determining the One-Dimensional Kernel of the Viscoelasticity Equation in a Bounded Domain. Mathematical Notes, 2015, vol. 97, no. 6 , pp. 867-877. DOI: $10.1134 /$ S0001434615050223

6. Colombo F., Guidetti D. An Inverse Problem for a Phase-Field Model in Sobolev Spaces. Nonlinear Elliptic and Parabolic Problems. Progress in Nonlinear Differential Equations and Their Applications, Basel, Birkhäuser Verlag, 2005, vol. 64, pp. 189-210.

7. Guidetti D., Lorenzi A. A Mixed Type Identification Problem Related to a Phase-Field Model with Memory. Osaka Journal of Mathematics, 2007, vol. 44, pp. 579-613.

8. Colombo F., Guidetti D. A Global in Time Existence and Uniqueness Result for a Semilinear Integrodifferential Parabolic Inverse Problem in Sobolev Spaces. Mathematical Models and Methods in Applied Sciences, 2007, vol. 17, no. 4, pp. 537-565. DOI: $10.1142 / \mathrm{S} 0218202507002017$

9. Colombo F. On Some Methods to Solve Integro-Differential Inverse Problems of Parabolic Type. Bulletin of the South Ural State University. Series: Mathematical Modelling, Programming and Computer Software, 2015, vol. 8, no. 3, pp. 95-115.

10. Favini A., Lorenzi A. Identication Problems for Singular Integro-Differential Equations of Parabolic Type. Nonlinear Analysis, 2004, vol. 56, no. 6, pp. 879-904. DOI: $10.1016 /$ j.na.2003.10.018

11. Lorenzi A., Tanabe H. Inverse and Direct Problems for Nonautonomous Degenerate IntegroDifferential Equations of Parabolic Type with Dirichlet Boundary Conditions. Differential Equations: Inverse and Direct Problems. Lecture Notes in Pure and Applied Mathematics, Boca Raton, London, N.Y., Chapman and Hall/CRC Taylor and Francis Group, 2006, vol. 251, pp. 197-244.

12. Abaseeva N., Lorenzi A. Identification Problems for Nonclassical Integro-Differential Parabolic Equations. Journal of Inverse and Ill-Posed Problems, 2005, vol. 13, no. 6, pp. 513-535. DOI: $10.1515 / 156939405775199523$

13. Asanov A., Atamanov E.R. An Inverse Problem for a Pseudoparabolic Integro-Defferential Operator Equation. Siberian Mathematical Journal, 1995, vol. 38, no. 4, pp. 645-655. DOI: $10.1007 / \mathrm{BF} 02107322$

14. Avdonin S.A., Ivanov S.A., Wang J. Inverse Problems for the Heat Equation with Memory, 2017, 10 p. Available at: https://arxiv.org/abs/1612.02129 (accessed February 09, 2018).

15. Pandolfi L. Identification of the Relaxation Kernel in Diffusion Processes and Viscoelasticity with Memory via Deconvolution, 2016, 15 p. Available at: https://arxiv.org/abs/1603.04321 (accessed February 09, 2018).

16. Denisov A.M. An Inverse Problem for a Quasilinear Integro-Differential Equation. Differential Equations, 2001, vol. 37, no. 10, pp. 1420-1426. DOI: 10.1023/A:1013320315508

17. Triebel H. Interpolation Theory. Function Spaces. Differential Operators. Berlin: VEB Deutscher Verlag der Wissenschaften, 1978. 
18. Ladyzhenskaya O.A, Ural'tseva N.N. Linear and Quasilinear Elliptic Equations. N.Y., Academic Press, 2016.

19. Gilbarg D., Trudinger N. Ellipticheskie differentsial'nye uravneniya s chastnymi proizvodnymi vtorogo poryadka [Elliptic Differential Equation with Partial Derivative of the Second Order]. Moscow, Nauka, 1989.

20. Maugeri A., Palagachev D.K., Softova L.G. Elliptic and Parabolic Equations with Discontinuous Coefficients. Berlin, Wiley-VCH Verlag, 2000. DOI: 10.1002/3527600868

Received January 30, 2018

УДК 517.956

DOI: $10.14529 / \mathrm{mmp} 180105$

\section{ОБРАТНЫЕ ЗАДАЧИ ДЛЯ МАТЕМАТИЧЕСКИХ МОДЕЛЕЙ КВАЗИСТАЦИОНАРНЫХ ЭЛЕКТРОМАГНИТНЫХ ВОЛН В АНИЗОТРОПНЫХ НЕМЕТАЛЛИЧЕСКИХ СРЕДАХ С ДИСПЕРСИЕЙ}

\section{С.Г. Пятков ${ }^{1,2}$, С.Н. Шергин ${ }^{1}$}

${ }^{1}$ Югорский государственный университет, г. Ханты-Мансийск, Российская Федерация

${ }^{2}$ Южно-Уральский государственный университет, г. Челябинск, Российская Федерация

В работе рассматриваются обратные задачи эволюционного типа для математических моделей квазистационарных электромагнитных волн. В модели предполагается, что длина волны мала по сравнению с пространственными неоднородностями. Вводя электрический и магнитный потенциал получаем эллиптическое уравнение второго порядка по пространственным переменным, содержащее интегральные слагаемые типа свертки по времени. После дифференцирования по времени задача сводится к уравнению составного типа с интегральным слагаемым. Определению вместе с решением подлежат неизвестные коэффициенты в интегральном операторе. Дополнительно к краевым условиям задаются условия переопределения в виде заданного набора функционалов от решения, которые могут иметь произвольный вид (интегралы от решения с весом, значения решения в отдельных точках и пр.). В качестве основных пространств рассматриваются пространства С.Л. Соболева. Доказываются теоремы о существовании и единственности решения поставленной задачи в целом по времени, приводится оценка устойчивости.

Ключевые слова: уравнения соболевского типа; эллиптическое уравнение; уравнения с памятью; обратная задача; краевая задача.

\section{Литература}

1. Свешников, А.Г. Линейные и нелинейные уравнения соболевского типа / А.Г. Свешников, А.Б. Альшин, М.О. Корпусов, Ю.Д. Плетнер. - М.: Физматлитература, 2007.

2. Габов, С.А. Линейные задачи теории нестационарных внутренних волн / С.А. Габов, А.Г. Свешников. - М.: Наука, 1990.

3. Lorenzi, A. Direct and Inverse Problems in the Theory of Materials with Memory / A. Lorenzi, I. Paparone // Rendiconti del Seminario matematico della Universita di Padova. - 1992. V. 87. - P. 105-138. 
4. Janno, J. Inverse Problems for Identification of Memory Kernels in Viscoelasticity / J. Janno, L. Von Wolfersdorf // Mathematical Methods in the Applied Sciences. - 1997. - V. 20. P. 291-314.

5. Durdiev, D.K. Inverse Problem of Determining the One-Dimensional Kernel of the Viscoelasticity Equation in a Bounded Domain / D.K. Durdiev, Zh.Sh. Safarov // Mathematical Notes. - 2015. - V. 97, № 6. - P. 867-877.

6. Colombo, F. An Inverse Problem for a Phase-Field Model in Sobolev Spaces. Nonlinear Elliptic and Parabolic Problems / F. Colombo, D. Guidetti // Progress in Nonlinear Differential Equations and Their Applications. - V. 64. - Basel: Birkhäuser Verlag, 2005. P. $189-210$.

7. Guidetti, D. A Mixed Type Identification Problem Related to a Phase-Field Model with Memory / D. Guidetti, A. Lorenzi // Osaka Journal of Mathematics. - 2007. - V. 44. P. 579-613.

8. Colombo, F. A Global in Time Existence and Uniqueness Result for a Semilinear Integrodifferential Parabolic Inverse Problem in Sobolev Spaces / F. Colombo, D. Guidetti // Mathematical Models and Methods in Applied Sciences. - 2007. - V. 17, № 4. - P. 537-565.

9. Коломбо, Ф. О некоторых методах решения интегрально-дифференциальных обратных задач параболического типа / Ф. Коломбо // Вестник ЮУрГУ. Серия: Математическое моделирование и программирование. - 2015. - Т. 8, № 3. - С. 95-115.

10. Favini, A. Identication Problems for Singular Integro-Differential Equations of Parabolic Type / A. Favini, A. Lorenzi // Nonlinear Analysis. - 2004. - V. 56, № 6. - P. 879-904.

11. Lorenzi, A. Inverse and Direct Problems for Nonautonomous Degenerate Integro-Differential Equations of Parabolic Type with Dirichlet Boundary Conditions / A. Lorenzi, H. Tanabe // Differential Equations: Inverse and Direct Problems. Lecture Notes in Pure and Applied Mathematics. - Boca Raton, London, N.Y.: Chapman and Hall/CRC Taylor and Francis Group, 2006. - V. 251. - P. 197-244.

12. Abaseeva, N. Identification Problems for Nonclassical Integro-Differential Parabolic Equations / N. Abaseeva, A. Lorenzi // Journal of Inverse and Ill-Posed Problems. - 2005. V. 13, № 6. - P. 513-535.

13. Асанов, А. Обратная задача для операторного интегро-дифференциального псевдопараболического уравнения / А. Асанов, Э.Р. Атаманов // Сибирский математический журнал. - 1995. - Т. 36, № 4. - С. 752-762.

14. Avdonin, S.A. Inverse Problems for the Heat Equation with Memory / S.A. Avdonin, S.A. Ivanov, J. Wang. - 2017. - 10 p. - URL: https://arxiv.org/abs/1612.02129 (дата обращения: 9 февраля 2018 г.)

15. Pandolfi, L. Identification of the Relaxation Kernel in Diffusion Processes and Viscoelasticity with Memory via Deconvolution / L. Pandolfi. - 2016. - 15 p. - URL: https://arxiv.org/abs/1603.04321 (дата обращения: 9 февраля 2018 г.)

16. Денисов, А.М. Обратная задача для квазилинейного интегро-дифференциального уравнения / А.М. Денисов // Дифференциальные уравнения. - 2001. - Т. 37, № 10. C. $1350-1356$.

17. Triebel, H. Interpolation Theory. Function Spaces. Differential Operators / H. Triebel. Berlin: VEB Deutscher Verlag der Wissenschaften, 1978.

18. Ладыженская, О.А. Линейные и квазилинейные уравнения эллиптического типа О.А. Ладыженская, Н.Н. Уральцева. - М.: Наука, 1973. 
19. Гилбарг, Д. Эллиптические дифференциальные уравнения с частными производными второго порядка / Д. Гилбарг, Н. Трудингер. - М.: Наука, 1989.

20. Maugeri, A. Elliptic and Parabolic Equations with Discontinuous Coefficients / A. Maugeri, D.K. Palagachev, L.G. Softova. - Berlin: Wiley-VCH Verlag, 2000.

Сергей Григорьевич Пятков, доктор физико-математических наук, заведующий кафедрой «Высшая математика», Югорский государственный университет (г. Ханты-Мансийск, Российская Федерация); научно-исследовательская лаборатория «Неклассические уравнения математической физики», Южно-Уральский государственный университет (г. Челябинск, Российская Федерация), S_pyatkov@ugrasu.ru.

Сергей Николаевич Шергин, аспирант, кафедра «Высшая математика», Югорский государственный университет (г. Ханты-Мансийск, Российская Федерация), ssn@ugrasu.ru.

Поступила в редакцию 30 января 2018 г. 